\title{
JAK2 mediates lung fibrosis, pulmonary vascular remodelling and hypertension in idiopathic pulmonary fibrosis: an experimental study
}

\author{
Javier Milara, ${ }^{1,2,3}$ Beatriz Ballester, ${ }^{3,4}$ Anselm Morell, ${ }^{4}$ José L Ortiz, ${ }^{4}$ Juan Escrivá, ${ }^{5}$ \\ Estrella Fernández, ${ }_{1}^{6}$ Francisco Perez-Vizcaino, ${ }^{3,7}$ Angel Cogolludo, ${ }^{3,7}$ Enrique Pastor, ${ }^{8}$ \\ Enrique Artigues, ${ }^{9}$ Esteban Morcillo, ${ }^{3,4,10}$ Julio Cortijo ${ }^{3,11}$
}

\begin{abstract}
- Additional material is published online only. To view please visit the journal online (http://dx.doi.org/10.1136/ thoraxjn-2017-210728).

For numbered affiliations see end of article.
\end{abstract}

\section{Correspondence to} Dr Javier Milara, Unidad de Investigación Clínica, Consorcio Hospital General Universitario, Valencia E-46014, Spain; xmilara@hotmail.com

$\mathrm{JM}$ and $\mathrm{BB}$ contributed equally.

Received 4 July 2017 Revised 11 January 2018 Accepted 22 January 2018 Published Online First 10 February 2018
Check for updates

To cite: Milara J, Ballester $B$ Morell A, et al. Thorax

2018:73:519-529.

\section{ABSTRACT}

Background Pulmonary hypertension $(\mathrm{PH})$ is a common disorder in patients with idiopathic pulmonary fibrosis (IPF) and portends a poor prognosis. Recent studies using vasodilators approved for $\mathrm{PH}$ have failed in improving IPF mainly due to ventilation (V)/perfusion $(Q)$ mismatching and oxygen desaturation. Janus kinase type 2 (JAK2) is a non-receptor tyrosine kinase activated by a broad spectrum of profibrotic and vasoactive mediators, but its role in $\mathrm{PH}$ associated to $\mathrm{PH}$ is unknown.

Objective The study of JAK2 as potential target to treat $\mathrm{PH}$ in IPF.

Methods and results JAK2 expression was increased in pulmonary arteries (PAs) from IPF $(n=10 ; 1.93-$ fold; $P=0.0011)$ and $I P F+P H(n=9 ; 2.65$-fold; $P<0.0001)$ compared with PA from control subjects $(n=10)$. PA remodelling was evaluated in human pulmonary artery endothelial cells (HPAECS) and human pulmonary artery smooth muscle cells (HPASMCs) from patients with IPF in vitro treated with the JAK2 inhibitor JSI-124 or siRNA-JAK2 and stimulated with transforming growth factor beta. Both JSI-124 and siRNA-JAK2 inhibited the HPAEC to mesenchymal transition and the HPASMCs to myofibroblast transition and proliferation. JAK2 inhibition induced small PA relaxation in precision-cut lung slice experiments. PA relaxation was dependent of the large conductance calcium-activated potassium channel $\left(\mathrm{BK}_{\mathrm{Ca}}\right)$. JAK2 inhibition activated $\mathrm{BK}_{\mathrm{Ca}}$ channels and reduced intracellular $\mathrm{Ca}^{2+}$. JSI-124 $1 \mathrm{mg} / \mathrm{kg} /$ day, reduced bleomycin-induced lung fibrosis, PA remodelling, right ventricular hypertrophy, PA hypertension and VIQ mismatching in rats. The animal studies followed the ARRIVE guidelines.

Conclusions JAK2 participates in PA remodelling and tension and may be an attractive target to treat IPF associated to $\mathrm{PH}$.

\section{BACKGROUND}

Idiopathic pulmonary fibrosis (IPF) is the most common idiopathic interstitial pulmonary disease with a median survival of 2.5-5 years after diagnosis. Pulmonary hypertension $(\mathrm{PH})$, defined by an elevation of mean pulmonary arterial pressure $\geq 25 \mathrm{~mm} \mathrm{Hg}$, in IPF portends a poor prognosis and accelerates lung function decline and death. ${ }^{1}$ Recent epidemiology studies recognise the prevalence of $\mathrm{PH}$ in IPF as $32 \%-84 \%$, depending on the stage of IPF progression. ${ }^{1}$

\section{Key messages}

What is the key question?

- To what extent does the Janus kinase type 2 (JAK2) pathway contribute to pulmonary hypertension (PH) associated to idiopathic pulmonary fibrosis (IPF)?

What is the bottom line?

- JAK2 is activated in pulmonary arteries from IPF and IPF+PH patients but not in healthy controls, and its inhibition ameliorates pulmonary artery remodelling, increases pulmonary artery relaxation and improves ventilation/perfusion mismatching.

Why read on?

- This is the first report that relates JAK2 with IPF and pulmonary artery remodelling identifying a novel target for therapeutics in IPF associated to $\mathrm{PH}$.

The increase of vascular muscularisation followed by fibrous vascular atrophy and pronounced intimal fibrosis of small pulmonary arteries are the hallmarks of $\mathrm{PH}$ in patients with IPF. ${ }^{2}$ Pulmonary artery remodelling in patients with IPF associated to $\mathrm{PH}$ are characterised by different cellular alterations, including endothelial dysfunction, ${ }^{3}$ the endothelial-to-mesenchymal transition (EnMT) as a source of myofibroblasts, ${ }^{4}$ as well as pulmonary artery smooth muscle proliferation and transition to myofibroblasts. ${ }^{5}$

Although PH is clearly associated with worse IPF outcomes, recent clinical trials have showed discouraging results when drugs approved for $\mathrm{PH}$ were used to treat IPF. This is the case of ET-1 receptor antagonists, prostacyclin analogues or soluble guanylate cyclase activators that failed in IPF clinical trials. ${ }^{6}$ Deleterious effects of vasodilators in hypoxic $\mathrm{PH}$, such as IPF, are attributed to increased oxygen desaturation mediated by the propensity to worsen ventilation/perfusion $(V / Q)$ matching by dilating vessels perfusing poorly ventilated lung units. ${ }^{7}$ Therefore, an ideal strategy to treat IPF associated to PH would be to inhibit lung fibrotic propagation and increase vasodilation 


\begin{tabular}{|c|c|c|c|c|}
\hline & $\begin{array}{l}\text { Control } \\
\text { donor } \\
\text { subjects } \\
(n=10)\end{array}$ & $\begin{array}{l}\text { IPF } \\
\text { patients }(n=10)\end{array}$ & $\begin{array}{l}\text { HP- } \\
\text { associated } \\
\text { IPF }(n=9)\end{array}$ & $P$ value \\
\hline Age (year), mean (SD) & $58.5(9.7)$ & $60.2(8.2)$ & $62.4(10.3)$ & NS \\
\hline Sex (male/female) & $8 / 2$ & $7 / 3$ & $7 / 2$ & \\
\hline \multicolumn{5}{|l|}{ Smoking } \\
\hline $\begin{array}{l}\text { Never smoked/ } \\
\text { smokers }\end{array}$ & $4 / 6$ & $3 / 7$ & $2 / 7$ & \\
\hline Pack-year (range) & $21(0-32)$ & $24.2(6-35)$ & $29(9-38)$ & NS \\
\hline $\mathrm{FEV}_{1}$, pred, mean (SD) & ND & $72.1(16.8)$ & $75.4(14.2)$ & NS \\
\hline FVC, \% pred, mean (SD) & ND & $71.8(8.5)$ & $68.3(7.8)$ & NS \\
\hline TLC, \% pred, mean (SD) & ND & $71.5(12.1)$ & $62.6(13.4)$ & NS \\
\hline DLco, \% pred, mean (SD) & ND & $47.1(11.5)$ & $39.5(13.4)$ & NS \\
\hline $\begin{array}{l}\text { Ground glass \%, } \\
\text { mean (SD) }\end{array}$ & 0 & $22.4(14.2)$ & $31.2(8.5)$ & $<0.001$ * \\
\hline $\begin{array}{l}\text { Honeycombing \%, } \\
\text { mean (SD) }\end{array}$ & 0 & $24.5(12.4)$ & $32.5(7.4)$ & $<0.001^{*}$ \\
\hline $\mathrm{PaO}_{2}, \mathrm{~mm} \mathrm{Hg}$, mean (SD) & $93.5(4.2)$ & $62.4(8.5)$ & $52.2(8.9)$ & $<0.001$ * \\
\hline $\begin{array}{l}\text { mPAP mm Hg/L/min, } \\
\text { mean (SD) }\end{array}$ & ND & $19.4(3.5)$ & $47.4(6.7)$ & $<0.01 \dagger$ \\
\hline NAC (y/n) & $0 / 10$ & $4 / 6$ & $1 / 8$ & \\
\hline Pirfenidone (y/n) & $0 / 10$ & $6 / 4$ & $4 / 5$ & \\
\hline
\end{tabular}

${ }^{*}$ Compared with control donors.

tCompared with patients with IPF.

Data are means (SD). N-acetyl-I-cysteine (NAC)/pirfenidone refers to patients who received this treatment at the time of pulmonary biopsy.

$\%$ pred, \% predicted; DLco, diffusion capacity of the lung for carbon monoxide; mPAP, mean pulmonary arterial pressure; ND, not determined; NS, not significance between groups $(P>0.05)$; pack-year, 1 year of smoking 20 cigarettes per day; $\mathrm{PaO}_{2}$, arterial blood oxygen pressure; TLC, total lung capacity; ground glass $\%, \%$ of pulmonary parenchyma with ground glass on a CT image; honeycombing $\%, \%$ of pulmonary parenchyma with honeycombing on a $\mathrm{CT}$ image.

preferably in those areas well ventilated but not in poorly ventilated areas.

JAK2/STAT3 pathway is activated in a broad range of fibrotic disorders such as myelofibrosis, skin, liver, myocardial and kidney fibrosis fibrosis. ${ }^{8-12}$ Janus kinase (JAK)-2 is a key regulator of cytokine signalling, and alterations of JAK2 signalling cause profound changes in response to cytokine stimulation. Transforming growth factor $\beta 1$ (TGF $\beta 1$ ) signalling can induce phosphorylation and activation of JAK2, which then interacts and phosphorylates STAT3 to induce fibrotic responses. ${ }^{12}$ Interestingly, JAK2 can be activated by other profibrotic mediators such as plateled-derived growth factor (PDGF), vascular endothelial growth factor (VEGF), interleukin (IL)-6, IL-13, angiotensin II (AT2), 5-HT and ET-1, all of them activated in IPF and $\mathrm{PH}$ and with the capacity to produce pulmonary vasoconstriction (the case of 5-HT, ET-1 and AT2). ${ }^{13}{ }^{14}$ However, the role of JAK2 in IPF and PH is poorly understood. In contrast, STAT3 phosphorylation has been observed in fibrotic lung tissue from patients with IPF and participates in fibroblast to myofibroblast transition and lung epithelial cell damage being an attractive target to treat IPF. ${ }^{15-17}$ In this work, we analysed the participation of JAK2 as lung profibrotic marker, activator of pulmonary artery remodelling of IPF patients as well as the potential of JAK2 inhibition as target to treat IPF and the associated PH.

As several JAK2 inhibitors are currently evaluated in clinical trials for malignancies and inflammatory diseases, the antifibrotic effects in experimental models of lung fibrosis associated to $\mathrm{PH}$ may have direct translational implications.

\section{MATERIALS AND METHODS}

See the online supplementary for a more detailed version of these methods.

\section{Patients and cell culture}

Human lung tissue was obtained from patients with IPF associated to PH $(n=9)$ and IPF $(n=10)$ who underwent surgery for organ transplantation programme, and lung explant healthy control samples were obtained from organ transplant programme from University General Consortium Hospital of Valencia $(n=10)$. Informed written consent was obtained from each participant. See online supplementary for details. Cellular experiments were performed in primary human pulmonary artery endothelial cells (HPAECs) and human pulmonary artery smooth muscle cells (HPASMCs) as previously outlined. ${ }^{18}$ See online supplementary for further details.

\section{Immunochemistry, immunofluorescence and western blotting} Collagen type I (Col I), $\alpha$-smooth muscle actin ( $\alpha$-SMA), CD31, JAK2/phospho-JAK2， STAT3/phosho-STAT3， SMAD3/phosphor-SMAD3 and MLCK/phosphor-MLCK were detected in human lung tissue or in pulmonary artery rings by immunohistochemistry, immunofluorescence or western blot as outlined previously. ${ }^{19}$ Lung slices were stained with Masson's trichrome to evaluate severity of lung fibrosis that was scored on a scale from 0 (normal lung) to 8 (total fibrotic obliteration of fields) according to Ashcroft score. ${ }^{20}$ Details are described in the online supplementary.

\section{Real-time RT-PCR and siRNA experiments}

Total RNA was obtained from pulmonary arteries or culture cells. The relative quantification of different transcripts was determined using the $2^{-\Delta \Delta \mathrm{Ct}}$ method with $\beta$-actin as the endogenous control and normalised to a control group, as described previously. ${ }^{21}$

HPAECs and HPASMCs cells were transfected with siRNA $(50 \mathrm{nM})$ of scrambled siRNA control or with JAK2 gene-targeted siRNA. The transfection reagent used was lipofectamine-2000 (Invitrogen, Paisley, UK) at a final concentration of $2 \mu \mathrm{g} / \mathrm{mL}$. Details are described in the online supplementary.

\section{Pulmonary artery functional studies, intracellular free $\mathrm{Ca} 2+$ measurements and electrophysiological studies}

Human precision-cut lung slices from control subjects, IPF and $\mathrm{IPF}+\mathrm{PH}$ patients were obtained. Slices with pulmonary arteries of approximately $100-300 \mu \mathrm{m}$ of internal diameter were obtained as previously described. ${ }^{22}$ Intracellular free calcium concentration $\left(\left[\mathrm{Ca}^{2+}\right]_{\mathrm{i}}\right)$ was measured in HPASMCs by epifluorescence microscopy as we previously outlined. ${ }^{23}$ Membrane currents were recorded in rat PASMCs using the whole-cell configuration of the patch clamp technique as previously outlined..$^{24}$ Details are described in the online supplementary.

\section{Intratracheal bleomycin animal model}

Animal experimentation and handling were performed in accordance with the guidelines of the Committee of Animal Ethics and Well-Being of the University of Valencia (Valencia, Spain). The animal studies followed the ARRIVE guidelines. ${ }^{25}$ A single dose of $3.75 \mathrm{U} / \mathrm{kg}$ bleomycin was administered intratracheally at day 1 of the experimental procedure. ${ }^{19}$ JSI-124 

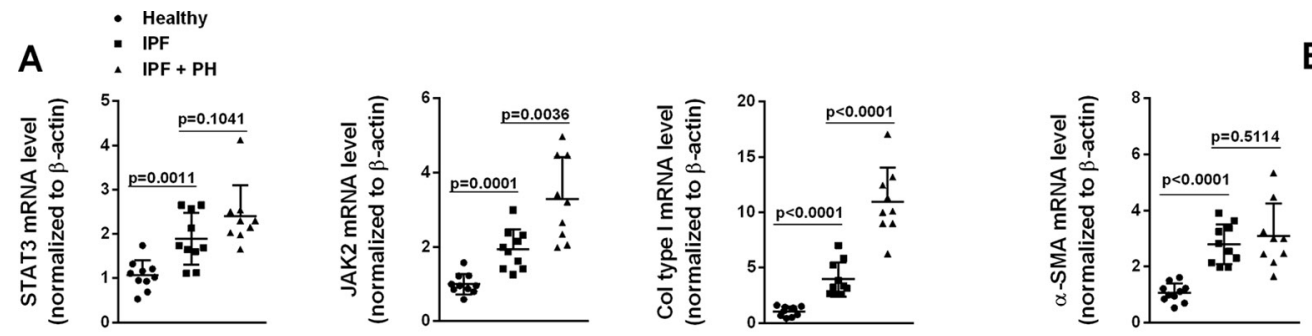

B
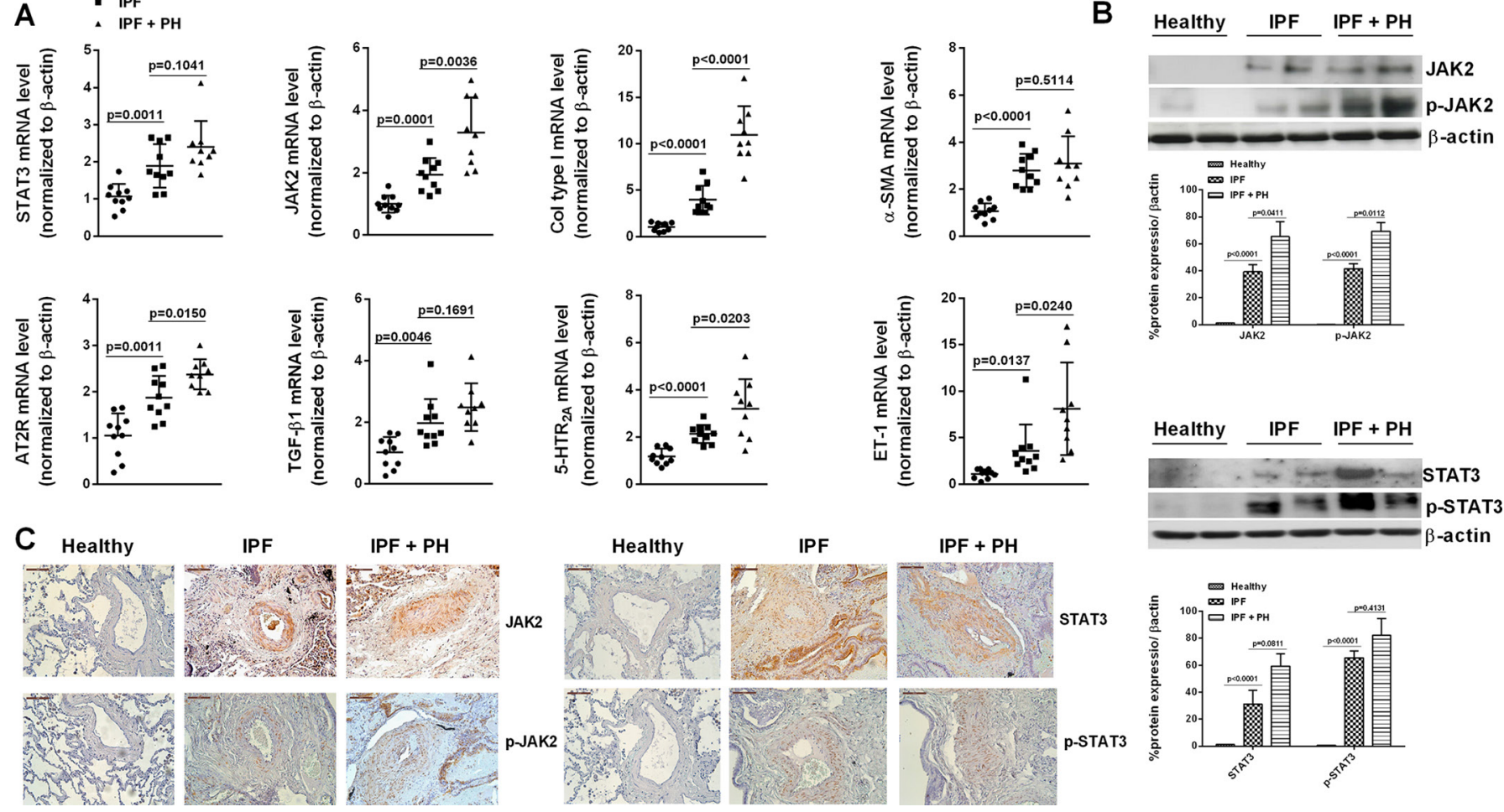

Figure 1 Expression and localisation of JAK2 in pulmonary arteries from patients with idiopathic pulmonary fibrosis (IPF). Isolated pulmonary arteries from control subjects $(n=10)$, IPF $(n=10)$ and IPF+PH patients $(n=9)$ was obtained. (A) Gene mRNA expression of JAK2, STAT3, collagen type I, $\alpha$-SMA, AT2R, TGF $\beta 1,5-H T R_{2 A}$ and ET-1 gene expression was analysed by real-time PCR. (B) Protein expression of JAK2/p-JAK2 and STAT3/p-STAT3 analysed by western blot. (C) Immunohistochemistry of JAK2/p-JAK2 and STAT3/p-STAT3. Scale bar: $100 \mu \mathrm{m}$. The lgG isotype control was negative (data not shown). Data are expressed as the ratio to $\beta$-actin. Data are presented as median with IQR. ' $P$ ' exact values were obtained following Kruskal-Wallis test. $\alpha$-SMA, $\alpha$-smooth muscle actin; JAK2, Janus kinase type 2; PH, pulmonary hypertension; TGF $\beta 1$, transforming growth factor $\beta 1$.

$1 \mathrm{mg} / \mathrm{kg} /$ day intraperitoneal (i.p.) ${ }^{26}$ was administered from day 7 to day 28 of procedure as therapeutic protocol. Pulmonary perfusion $(Q)$, ventilation $(V)$ and the $V / Q$ ratio were analysed using small animal CT (micro-CT) and single-photon emission CT (SPECT; Oncovision micro-CT-SPECT-PET Imaging System; Albira, Valencia, Spain) imaging with the radioisotopes diethylene-triamine-pentaacetate $\left(10 \mathrm{mCi}\right.$; DTPA-Tc99 $\left.{ }^{\mathrm{m}}\right)$ for ventilation and $0.5-1 \mathrm{mCi}$ macroaggregated albumin (MAA)-Tc $99^{\mathrm{m}}$ for perfusion, as outlined previously with modifications. ${ }^{18}$ Details are described in the online supplementary.

\section{Statistical analysis}

The Kruskal-Wallis test followed by Dunn's post hoc tests were used when more than two groups were compared in human studies. Two-tailed Student's paired t-tests were used to compare two groups of dependent samples in the animal and cell studies and unpaired t-tests for independent samples. Multiple comparisons were analysed by a one-way or two-way analysis of variance followed by Bonferroni post hoc tests. Details are described in the online supplementary.

\section{RESULTS}

\section{JAK2 is increased and activated in lungs and pulmonary} arteries from patients with IPF

The JAK2 and STAT3 mRNA transcript levels were increased in isolated pulmonary arteries of IPF patients with (2.65 fold; $\mathrm{P}<0.0001)$ and without $\mathrm{PH}(1.94$ fold; $\mathrm{P}=0.0001)$ compared with control subjects (see clinical data in table 1 and figure $1 \mathrm{~A})$. Pulmonary arteries from patients with IPF showed higher JAK2
(39\% higher; $\mathrm{P}<0.0001)$ and STAT3 (31\% higher; $\mathrm{P}<0.0001)$ protein expression than in control subjects. The active phosphorylated forms of JAK2 (42\% higher; $\mathrm{P}<0.0001 \mathrm{vs}$ control) and STAT3 (66\% higher; $\mathrm{P}<0.0001$ vs control) were upregulated in patients with IPF and significantly overexpressed in pulmonary arteries from IPF $+\mathrm{PH}$ patients in the case of JAK2 (70\% higher; $\mathrm{P}=0.0112$ vs IPF; figure $1 \mathrm{~B})$. Lung fibrotic remodelling markers such as Col I, $\alpha$-SMA and TGF $\beta 1$, and vasoactive profibrotic markers such as ET-1, AT2R and $5-\mathrm{HTR}_{2 \mathrm{~A}}$ were also increased in IPF and IPF + PH pulmonary arteries (figure 1A).

Lung section immunohistochemistry showed a weak JAK2 and STAT3 expression in control subjects, mainly localised in alveolar macrophages (figure 1C), but not detected in pulmonary arteries. In contrast, lung sections from IPF and IPF $+\mathrm{PH}$ patients showed elevated expression of JAK2 and STAT3 localised in the intima and media but not in the adventitia of small pulmonary arteries (figure 1C). Phosphorylated forms of JAK2 and STAT3 were located in the cell nucleus of pulmonary artery cells. JAK2, STAT3 and their phosphorylated forms were also detected in fibroblasts and alveolar type II cells from fibrotic areas (online supplementary figure 1).

\section{JAK2 contributes to pulmonary artery remodelling in ex vivo human pulmonary arteries from patients with IPF}

In other ex vivo experiments (see online supplementary for experimental design details), pulmonary artery ring explants from patients with IPF were cultured and stimulated with $5 \mathrm{ng} / \mathrm{mL}$ TGF $\beta 1$ for 72 hours in the presence or absence of the JAK2 inhibitor JSI-124 $(10 \mathrm{nM}-1 \mu \mathrm{M})$. TGF $\beta 1$ treatment 
A
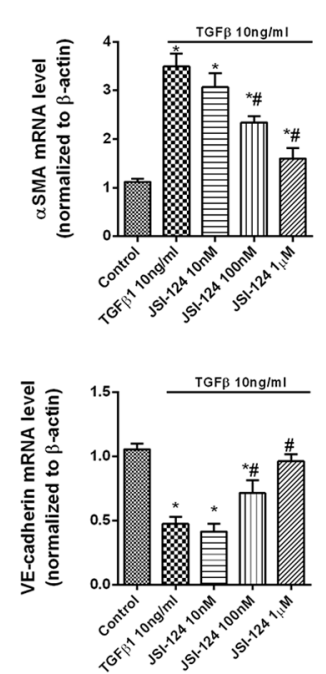

C

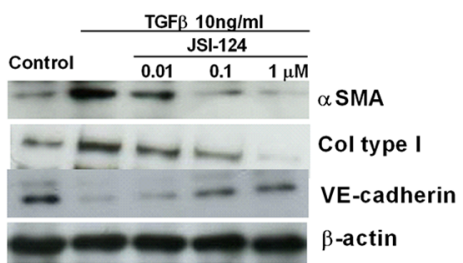

B

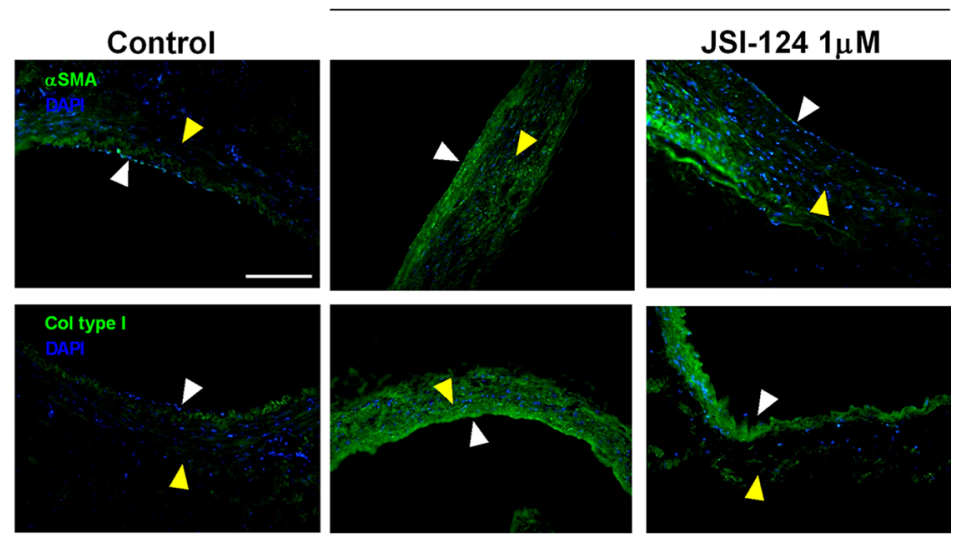

Figure 2 JAK2 inhibition reduced transforming growth factor (TGF) $\beta 1$-induced ex vivo PA ring remodelling. PA rings from (A and B) patients with IPF $(n=4)$ were incubated with the JAK2 inhibitor JSI-124 (10 nM-1 $\mu$ M) for 1 hour and then stimulated with $5 \mathrm{ng} / \mathrm{mL}$ TGF $\beta 1$ for 72 hours. Artery rings were homogenised to extract RNA for gene expression analysis (A), embedded in paraffin for immunofluorescence analysis (B) or western blot analysis (C). Scale bar: $150 \mu \mathrm{m}$. Yellow arrows indicate adventitial and smooth muscle layers. White arrows indicate endothelial cells. Four arterial rings per patient were used. The results are shown as mean \pm SE Two-way analysis of variance followed by Bonferroni post hoc tests. ${ }^{*} \mathrm{P}<0.05$ compared with control; \#P<0.05 compared with TGF $\beta 1$. $\alpha$-SMA, $\alpha$-smooth muscle actin; JAK2, Janus kinase type 2; IPF, idiopathic pulmonary fibrosis; PA, pulmonary artery; TGF $\beta 1$; transforming growth factor $\beta 1$.

resulted in decreased expression of the endothelial markers VE-cadherin $(-0.47$-fold vs control; $\mathrm{P}<0.05)$ and eNOS $(-0.46$ fold vs control; $\mathrm{P}<0.05)$ and the increase of remodelling mesenchymal markers Col I (sixfold vs control; $\mathrm{P}<0.05$ ) and $\alpha$-SMA (3.5-fold vs control; $\mathrm{P}<0.05$ (figure $2 \mathrm{~A}$ ) in both endothelial cells and cells located in the intima (figure $2 \mathrm{~B}$ ). JSI-124 inhibited the effect of TGF $\beta 1$ on the loss of endothelial markers and upregulation of the pulmonary artery remodelling markers at $100 \mathrm{nM}-1 \mu \mathrm{M}$ (figure $2 \mathrm{~A}, \mathrm{C}$ ), suggesting pulmonary artery antiremodelling properties in patients with IPF.

\section{JAK2 mediates TGF $\beta 1$-induced pulmonary artery endothelial- to-mesenchymal and smooth muscle cell to myofibroblast transitions}

The next experiments were designed to explore the effects of JAK2 on remodelling alterations of pulmonary arteries of IPF patients, including HPAECs and HPASMCs to mesenchymal transition. Incubating the HPAECs with TGF $\beta 1$ changed their endothelial phenotype to a mesenchymal/myofibroblast phenotype characterised by loss of the endothelial markers VE-cadherin, VEGFR1, FVIII and eNOS and an increase in the mesenchymal markers Col I, $\alpha$-SMA and vimentin (figure 3A). JAK2 gene silencing (siRNA-JAK2) or pharmacological inhibition of JAK2 using JSI-124, prevented these changes and maintained the endothelial phenotype $(\mathrm{P}<0.05$; figure 3A). TGF $\beta 1$ increased the expression of collagen type $\mathrm{I}$ and vimentin in HPASMCs; this effect was inhibited by siRNA-JAK2 and JSI-124 treated cells $(\mathrm{P}<0.05$; figure $3 \mathrm{~B})$. Furthermore, siRNA-JAK2 and JSI-124 treatments inhibited TGF $\beta 1$-induced HPASMC proliferation ( $\mathrm{P}<0.05$; figure $3 \mathrm{C}$ ). Adding $5 \mathrm{ng} / \mathrm{mL}$ TGF $\beta 1$ to HPAECs and HPASMCs from patients with IPF increased the phosphorylation of JAK2 and SMAD3, which was inhibited by siRNA-JAK2 and JSI-124 (figure 3D,E).

To analyse the phenotype characteristics of endothelial to mesenchymal transition, endothelial cells were immunostained with $\alpha$-SMA antibody. TGF $\beta 1$ produced $\alpha$-SMA fibres that were inhibited by JSI-124 (figure 3F). Formation of $\alpha$-SMA fibres increased the capacity of cell contraction as assessed by traction microscopy (figure $3 \mathrm{G}$ ) confirming the mesenchymal/myofibroblast phenotype (figure $3 \mathrm{G}$ ).

Pulmonary arteries from healthy controls showed a lack of JAK2, p-STAT3 and $\alpha$-SMA expression and positive immunostaining for CD31 in endothelial layer (online supplementary figures 2 and 3 ). In contrast to normal human pulmonary arteries, those from IPF and IPF $+\mathrm{PH}$ patients showed coimmunostaining with CD31 and JAK2/p-STAT3 and with $\alpha$-SMA and JAK2/pSTAT3 in endothelial cells, as well as in the intima, suggesting a role for EnMT in pulmonary remodelling (online supplementary figures 2 and 3 ). 
A $\quad$ siRnA(-)

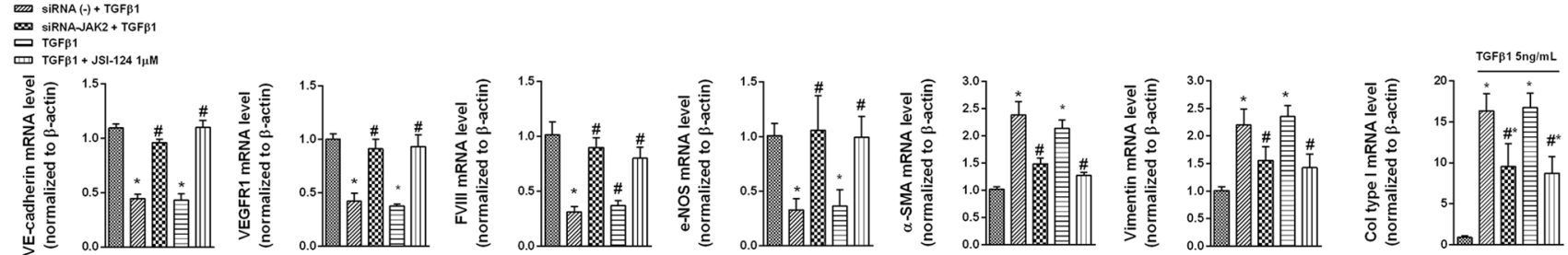

B

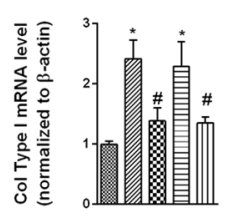

E

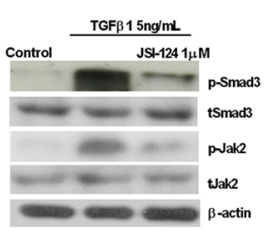

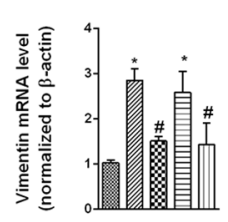

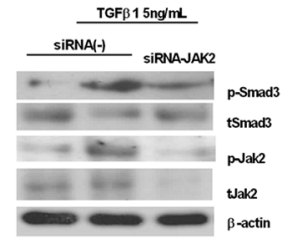

C

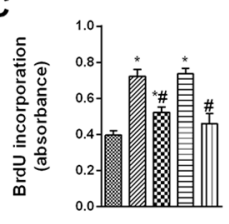

$\mathbf{F}$

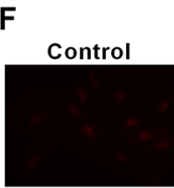

D
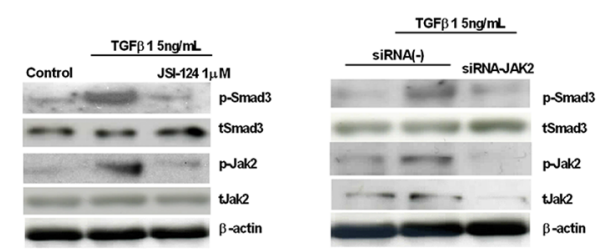

TGF $\beta 15 \mathrm{ng} / \mathrm{ml}$

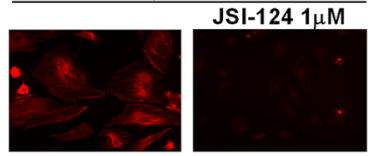

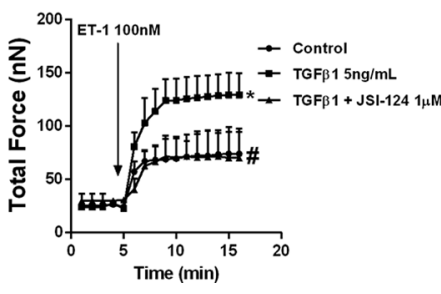

Figure 3 Effects of JAK2 inhibition on TGF 31 -induced endothelial-mesenchymal and smooth muscle cell-mesenchymal transition. (A) Human PA endothelial cells (HPAECs) and (B and C) human PA smooth muscle cells (HPASMCs) were isolated from PAs of patients with IPF ( $n=4)$. The cells were incubated with JSI-124 (1 $\mu \mathrm{M})$ for 30 min or treated with siRNA to silence JAK2 gene. Cells were then stimulated with $5 \mathrm{ng} / \mathrm{mL}$ TGF $\beta 1$ for $(A) 72$ hours or (B) 48 hours. Endothelial and mesenchymal marker gene mRNA expression was analysed. (C) HPASMCs from patients with IPF were incubated with JSI-124 (1 $\mu \mathrm{M})$ for 30 min or treated with siRNA to silence JAK2 gene, and then stimulated with $5 \mathrm{ng} / \mathrm{mL}$ TGF 31 for 48 hours in 96 -well plates to measure cell proliferation with the bromodeoxyuridine (BrdU) assay. HPAECs (D) and HPASMCs (E) were incubated with JSI-124 (1 $\mu \mathrm{M})$ for 30 min or treated with siRNA to silence JAK2 gene, and then stimulated with $5 \mathrm{ng} / \mathrm{mL}$ TGF $\beta 1$ for 1 hour. Protein expression of total Jak2 and Smad3, and phosphorylated Jak2 and Smad3 were analysed together with the internal control $\beta$-actin by western blot. The results are shown as mean \pm SE of $\mathrm{n}=4$ cell populations from patients with IPF. (F) Immunofluorescence for $\alpha$-SMA in HPAECs stimulated with $5 \mathrm{ng} / \mathrm{mL}$ TGF $\beta 1$ in presence or absence of JSI-124 (1 $\mu \mathrm{M})$. (G) Discs with cultured HPAECs were incubated for 72 hours with $5 \mathrm{ng} / \mathrm{mL}$ TGF $\beta 1$ in presence or absence of JSI-124 (1 $\mu \mathrm{M})$. Then, a gel disk with cultured HPAECs was placed in the microscope and cells imaged with bright field illumination. The graph shows the time course of contractile response of HPAECs challenged with ET-1 (100 nM). Values are expressed as total force exerted by the cell on the substrate. Two-way analysis of variance followed by Bonferroni post hoc tests. ${ }^{*} \mathrm{P}<0.05$ compared with control; $\# \mathrm{P}<0.05$ compared with TGF $\beta 1$. $\alpha$-SMA, $\alpha$-smooth muscle actin; JAK2, Janus kinase type 2; PA, pulmonary artery; TGF $\beta 1$; transforming growth factor $\beta 1$.

\section{JAK2 inhibition promotes relaxant and anticontractile effects on pulmonary arteries from patients with IPF}

JSI-124 dose-dependently relaxed 5-HT precontracted pulmonary arteries to nearly $80 \%$ of maximum inhibition at $10 \mu \mathrm{M}$ (figure 4A). JSI-124 induced a direct relaxation on basal tone of IPF pulmonary arteries, near to $40 \%$ of maximum relaxant effect of papaverine (figure 4B). Pulmonary artery relaxant effects of JSI-124 were higher in pulmonary arteries from control subjects $\left(\mathrm{EC}_{50} 6.5 \pm 0.15 \mu \mathrm{M}\right.$, maximal inhibition, $78 \% \pm 6.4 \% ; \mathrm{P}<0.05$ vs IPF and IPF $+\mathrm{PH}$; figure $4 \mathrm{C})$ than in IPF $\left(\mathrm{EC}_{50} 5.9 \pm 0.12 \mu \mathrm{M}\right.$, maximal inhibition, $70 \% \pm 2.6 \%$; $\mathrm{P}<0.05$ vs control; figure $4 \mathrm{C})$ and $\mathrm{IPF}+\mathrm{PH}\left(\mathrm{EC}_{50} 5.8 \pm 0.1 \mu \mathrm{M}\right.$, maximal inhibition, $55 \% \pm 5.2 \% ; \mathrm{P}<0.05$ vs control; figure $4 \mathrm{C})$. In order to study the contribution of the endothelium in vascular relaxation induced by JSI-124, pulmonary arteries from patients with IPF were pretreated with L-Noarg $1 \mu \mathrm{M}$ or with indomethacin. Neither L-Noarg nor indomethacin were able to reduce relaxant effects of JSI-124 (figure 4D). To analyse the contribution of potassium channels to the relaxant effects of JSI-124, cut lung slices were treated with tetraethylammonium (a non-selective potassium channels blocker), iberiotoxin (IBTX; an inhibitor of large conductance calcium-activated potassium channel $\left(\mathrm{BK}_{\mathrm{Ca}}\right)$ ) or charybdotoxin (an inhibitor of large conductance calcium-activated potassium channels and slowly inactivating voltage-gated potassium channels) before JSI-124. All potassium inhibitors reduced $\sim 55 \%$ relaxation effects of JASI- 124 , with the same potency and maximum effect, suggesting the participation of $\mathrm{BK}_{\mathrm{Ca}}$ channels in the relaxation process. To evaluate the effect of the JAK2 inhibitor on hypoxic pulmonary vasoconstriction (HPV), lung cut slices were incubated in hypoxic conditions $\left(95 \% \mathrm{~N}_{2}-5 \% \mathrm{CO}_{2}\right)$ during 1 hour, inducing a $25 \%-35 \%$ of the maximal response induced by $80 \mathrm{mM} \mathrm{KCl}$ (data not shown). After 1 hour of hypoxic conditions, JSI-124 showed a vasodilator effect that reach $50 \%$ in control arteries and $22 \%$ in IPF arteries, suggesting a predominant HPV inhibitor role in control arteries rather than in IPF arteries.

In other experiments, JSI-124 significantly inhibited 5-HT-induced contractions in control donors and patients with IPF (figure 4F,G). Importantly, the inhibitory effect of JSI-124 on 5 -HT-induced contraction was significantly higher in control subjects than in IPF cut lung slices (figure 4F, G; P<0.05).

\section{JAK2 inhibits $\mathrm{BK}_{\mathrm{Ca}}$ potassium currents and increases} intracellular $\mathrm{Ca}^{2+}$ in pulmonary artery smooth muscle cells Using electrophysiology records, we observed that JSI-124 $1 \mu \mathrm{M}$ increased $\mathrm{BK}_{\mathrm{Ca}}$ currents in isolated rat PASMCs $(\mathrm{P}<0.05$ vs control; figure $5 \mathrm{~A}, \mathrm{~B})$. The $\mathrm{BK}_{\mathrm{Ca}}$ inhibitor IBTX, suppressed JSI-124-induced $\mathrm{K}^{+}$currents (figure 5C,D) suggesting that JAK2 modulates the closure of $\mathrm{BK}_{\mathrm{Ca}}$ and that the inhibition of JAK2, 
A

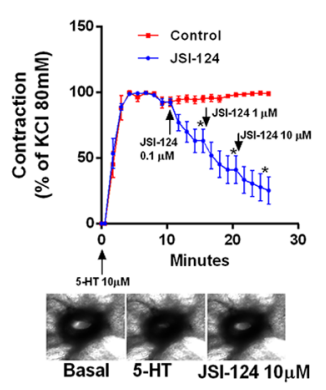

B

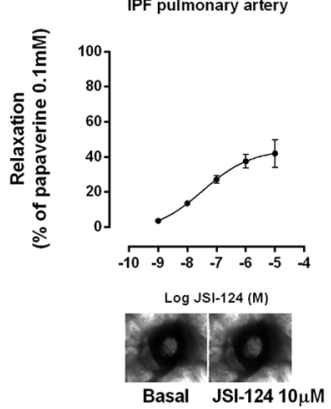

C

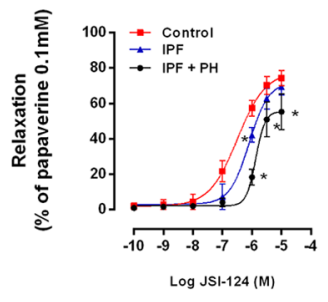

D

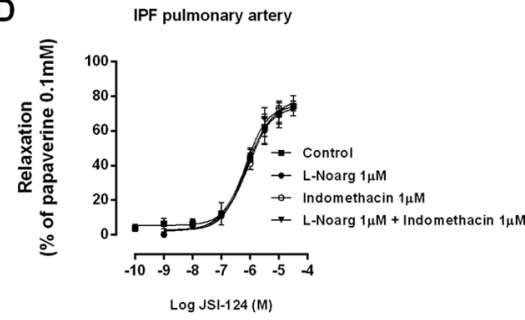

F

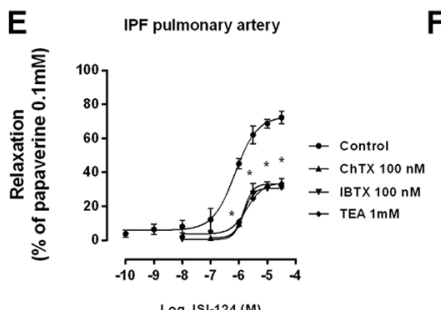

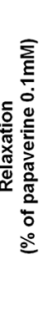

Hypoxic pulmong

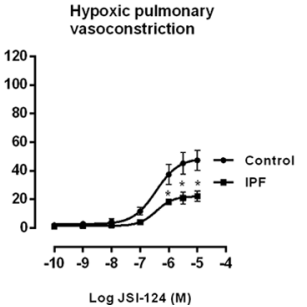

G

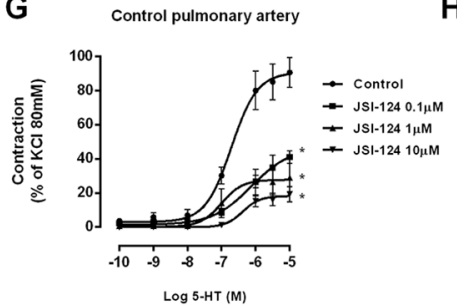

H

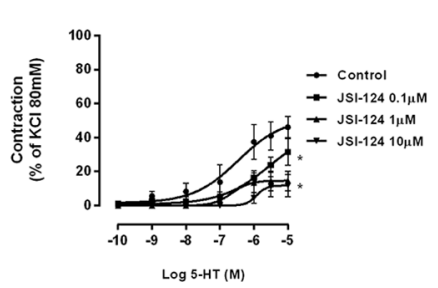

Figure 4 Relaxant effects of JAK2 inhibition on pulmonary arteries from patients with idiopathic pulmonary fibrosis (IPF). (A) Concentrationdependent relaxant curves of the JAK2 inhibitor JSI-124 on small pulmonary arteries precontracted with $10 \mu \mathrm{M}$ serotonin (5-HT) in precision lung cut slices from IPF $(n=6)$. (B) Direct relaxing effect of JSI-124 on basal tone of small pulmonary arteries of precision lung cut slices from IPF ( $n=6)$. (C) Concentration-dependent relaxant curves of the JAK2 inhibitor JSI-124 on small pulmonary arteries precontracted with 5-HT $1 \mu \mathrm{M}$ in precision lung cut slices from control donors $(n=10)$, IPF $(n=6)$ and IPF $+P H(n=6)$. (D) Precontracted $5-H T$ pulmonary arteries from cut lung slices of patients with IPF $(n=6)$ were incubated with the endothelial nitric synthase inhibitor $L-N o a r g$, the cyclooxygenase inhibitor indomethacin, $(E)$ with tetraethylammonium (TEA; a non-selective potassium channels blocker), iberiotoxin (IBTX; an inhibitor of large conductance calcium-activated potassium cannel $\left(\mathrm{BK}_{\left.\mathrm{C}_{\mathrm{a}}\right)}\right)$ or charybdotoxin (ChTX; an inhibitor of large conductance calcium-activated potassium channels and slowly inactivating voltage-gated potassium channels) for $15 \mathrm{~min}$, followed by the addition of growing concentrations of JSI-124. (F) Lung cut slices were incubated in hypoxic conditions $\left(95 \% \mathrm{~N}_{2}-5 \% \mathrm{CO}_{2}\right)$ during 1 hour, and cumulatively increasing concentrations of JSI-124 (from $0.01 \mathrm{nM}$ to $50 \mu \mathrm{M}$ ) were added in control $(\mathrm{n}=6)$ and IPF $(n=6)$ arteries. ( $G$ and H) Pulmonary arteries from precision lung cut slices from control donors $(n=10)$ and patients with IPF $(n=6)$ were incubated with JSI-124 for 30 min followed by increasing 5 -HT concentrations. The results are shown as mean \pm SE. Two-way analysis of variance followed by Bonferroni post hoc tests. ${ }^{*} \mathrm{P}<0.05$ versus control. JAK2, Janus kinase type 2; $\mathrm{PH}$, pulmonary hypertension.

using JSI-124, reactivates $\mathrm{BK}_{\mathrm{Ca}}$ and induces vascular relaxation. The inhibition of $\mathrm{BK}_{\mathrm{Ca}}$ channels increased cytoplasmic $\mathrm{Ca}^{2+}$ as we observed using IBTX $100 \mathrm{nM}$ as stimulus in HPASMCs from patients with IPF (figure 5F,G). IBTX-induced cytoplasmic $\mathrm{Ca}^{2+}$ was inhibited in cells preincubated with JSI-124 and in cells treated with siRNA-JAK2 $(\mathrm{P}<0.05$ vs IBTX stimulus; figure 5F,G). The increase of MLCK phosphorylation induced by 5 -HT in HPAECs from IPF patients was inhibited by JSI-124 as assessed by western blot and immunofluorescence (figure $5 \mathrm{H}, \mathrm{I}$ ). The expression of the $\mathrm{BK}_{\mathrm{Ca}} \alpha 1$ and $\mathrm{BK}_{\mathrm{Ca}} \beta 1$ decreased in pulmonary arteries from IPF and IPF $+\mathrm{PH}$ compared with control arteries (figure $5 \mathrm{~J}, \mathrm{~K}$ ).

\section{JAK2 mediates lung fibrosis, PA remodelling and hypertension} in rats treated with intratracheal bleomycin

Following 28 days of intratracheal bleomycin instillation, a marked lung fibrotic response was observed as it indicated the increase of Ashcroft score of lung histology ( $\mathrm{P}<0.05$ vs control; figure 6A,B). JSI-124 alleviated histologically observed multifocal fibrotic lesions, resulting in fewer organised and smaller foci and reduced septal enlargement with a diminished Ashcroft fibrosis score $(\mathrm{P}<0.05$ vs bleomycin group; figure $6 \mathrm{~A}, \mathrm{~B})$.

Right ventricular (RV) hypertrophy (RV/left ventricular $(\mathrm{LV})+$ septum) and pulmonary vascular remodelling developed following bleomycin treatment (figure 6A, C and D). By day 28 , PH was observed in the bleomycin group, as peak RV systolic pressure had increased from $20 \pm 3.6$ in control rats to $40.2 \pm 4.1 \mathrm{~mm} \mathrm{Hg}$ in the bleomycin group $(\mathrm{P}<0.05$ vs control; figure 6E). JSI-124 reduced RV hypertrophy, pulmonary vascular remodelling, and normalised $\mathrm{PH}$ to $24.5 \pm 5.9 \mathrm{~mm} \mathrm{Hg}$ at day $28(\mathrm{P}<0.05$ vs bleomycin group; figure $6 \mathrm{E})$. JSI- 124 also reduced collagen deposition, visualised by Masson's trichrome staining, and muscularisation in the walls of pulmonary arteries $(\mathrm{P}<0.05$ vs bleomycin group; figure $6 \mathrm{~A}, \mathrm{~B})$. Bleomycin induced JAK2, STAT3 and SMAD3 lung phosphorylations at day 28 that were inhibited by JSI-124 $(\mathrm{P}<0.05$ vs bleomycin group; figure $6 \mathrm{~F}-\mathrm{H})$.

PA sections immunostained with $\alpha$-SMA, JAK2, p-STAT3 and CD31 showed an endothelial layer marked with CD31 in control rats, and with $\alpha$-SMA, CD31 and JAK2/p-STAT3 in bleomycin-treated rats (online supplementary figures 4 and 5). Administration of JSI-124 to bleomycin-treated rats showed an endothelial layer marked by CD31, suggesting the inhibition of endothelial-to-mesenchymal transition in vivo (online supplementary figures 4 and 5).

Pulmonary ventilation and perfusion were significantly reduced in the bleomycin-treated group between day 7 and day 28 of the experimental procedure ( $88 \%$ ventilation reduction and $69 \%$ of perfusion reduction at day 28 (figure 7A,B). The JAK2 inhibitor JSI-124 was administered between day 7 and day 28 of the experimental procedure and improved pulmonary ventilation and perfusion in a similar degree between day 14 and day $28(45 \%$ of ventilation reduction and $41 \%$ of perfusion reduction at day 28 ; $\mathrm{P}<0.05$ vs bleomycin group; figure $7 \mathrm{~A}, \mathrm{~B})$. The relation between $V / Q$ was analysed at the end of experimental procedure (day 28). $V$ images were taken after breathing DTPA-Tc $99^{\mathrm{m}}$, and $Q$ images were taken after perfusing MAA-Tc $99^{\mathrm{m}}$. As expected, the $V / Q$ ratio was clearly impaired in the lungs of bleomycin-treated 

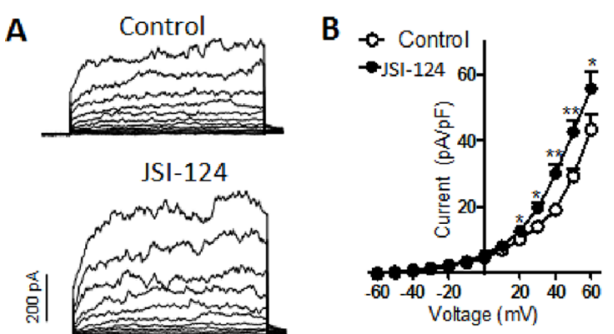

JSI-124

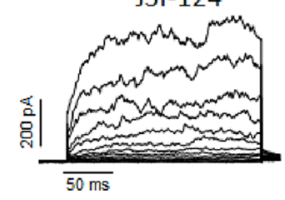

C

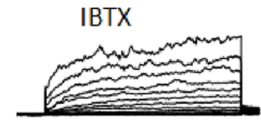

IBTX + JSI-124

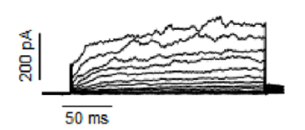

$\mathbf{E}$

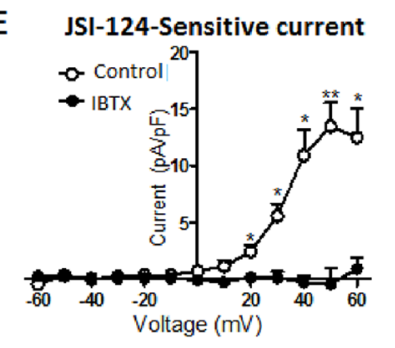

$\mathbf{F}$
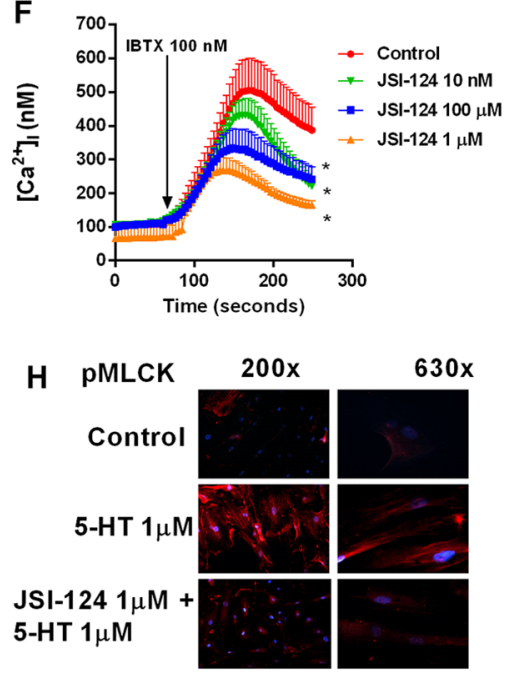

$J$

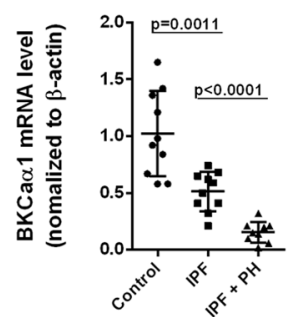

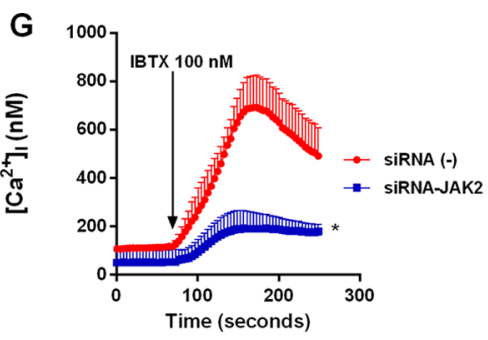

I

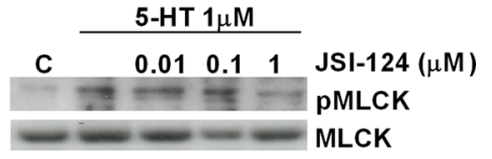

Figure 5 JAK2 inhibition augments BK ${ }_{C a}$ currents in pulmonary artery smooth muscle cells (PASMC). (A-E) Electrophysiological studies performed in PASMCs of rat pulmonary arteries (250-350 $\mu \mathrm{m}$ internal diameter) isolated from male Wistar rats. (A) Representative current traces for $200 \mathrm{~ms}$ depolarisation pulses from $-60 \mathrm{mV}$ to $+60 \mathrm{mV}$ in $10 \mathrm{mV}$ increments from a holding potential $-60 \mathrm{mV}$ before (control) and after JSI-124 $1 \mu \mathrm{M}$. (B) Current-voltage relationships of $\mathrm{K}^{+}$currents measured at the end of the pulse before (control) and after the addition of JSI-124 ( $\left.\mathrm{n}=5\right)$. Representative current traces (C) and current-voltage relationships (D) showing the lack of effect of JSI-124 in the presence of iberiotoxin (IBTX, $0.1 \mu \mathrm{M}, \mathrm{n}=5$ ). (E) JSI-124-sensitive current obtained by subtracting the current in the presence and in the absence of the drug in cells perfused with or without (control) IBTX. Results are means \pm SE. * and ** indicate $\mathrm{P}<0.05$ and $\mathrm{P}<0.01$ versus control, respectively (paired or unpaired Student's $\mathrm{t}$ test). (F and $\mathrm{G}$ ) Intracellular $\mathrm{Ca}^{2+}$ measured in human PASMCs from patients with IPF patients $(\mathrm{n}=3)$ using fura-2AM as $\mathrm{Ca}^{2+}$ indicator in a fluorescence microscopy. Cells were incubated with (F) JSI-124 (10 nM-1 $1 \mathrm{M}, 30$ min before stimulus) or (G) gene JAK2 silencing and stimulated with iberiotoxin (IBTX). Results are the mean \pm SE of $n=20$ cells per condition. ${ }^{*} P<0.05$ versus stimulus. (H and I) HPASMCs from patients with IPF ( $n=4$ ) incubated with JSI-124 and stimulated with serotonin (5-HT) $1 \mu \mathrm{M}$ for $30 \mathrm{~min}$. Levels of phosphorylated (H) and non-phosphorylated (I) myosin light-chain kinase were measured by immunofluorescence $(\mathrm{H})$ and western blot $(\mathrm{I})$. ( $\mathrm{J}$ and $\mathrm{K}) \mathrm{Gene}$ mRNA expression of $\mathrm{BK}_{\mathrm{C}_{\mathrm{C}}} \alpha 1$ and $\mathrm{BK}_{\mathrm{C}_{\mathrm{C}}} \beta 1$ was measured in pulmonary arteries from control subjects $(n=10)$, IPF $(n=10)$ and IPF+PH patients $(n=9)$. Data are presented as median with IQR. ' $P$ ' exact values were obtained following Kruskal-Wallis test. $\mathrm{BK}_{\mathrm{ca}^{\prime}}$ calcium-activated potassium channel; JAK2, Janus kinase type 2.

rats compared with that in control animals $(73.7 \%$ of reduction at day 28 vs control; $\mathrm{P}<0.05$ vs control; figure $7 \mathrm{C}-\mathrm{G}$ ). Therapeutic administration of JSI-124 $1 \mathrm{mg} / \mathrm{kg} /$ day from day 7 to day 28 improved the correlation of $V / Q(8.8 \%$ of reduction at day 28 vs bleomycin; $\mathrm{P}<0.05$ vs bleomycin group; figure $7 \mathrm{C}$ ). To compare with other vasodilators approved for $\mathrm{PH}$, bosentan was administered orally at $100 \mathrm{mg} / \mathrm{kg}$ between days 7 and 28 of the experimental procedure. Bosentan significantly improved lung perfusion (figure 7E). However, lung ventilation did not show a proportional improvement (figure 7D), so $V / Q$ was impaired. These results were supported by the analysis of arterial blood $\mathrm{O}_{2}$ pressure $\left(\mathrm{PaO}_{2}\right)$, arterial blood $\mathrm{CO}_{2}$ pressures and the alveolararterial $\mathrm{O}_{2}$ pressure difference $\left(\mathrm{AaDO}_{2}\right)$. JSI-124 improved $\mathrm{PaO}_{2}$ and restored $\mathrm{AaDO}_{2}$ to control values. In contrast, bosentan did not improve $\mathrm{PaO}_{2}$, sustaining elevated $\mathrm{AaDO}_{2}$ values that reflect uncoupled $V / Q$ (figure $7 \mathrm{H}$ ).

\section{DISCUSSION}

In this study, we analysed the effects of JAK2 on pulmonary fibrosis, pulmonary artery remodelling and contraction in an ex vivo/in vitro system of pulmonary arteries from patients with IPF with and without severe $\mathrm{PH}$. This work provide novel evidence of the overexpression of JAK2 and its phosphorylated form in lung tissue and pulmonary arteries from IPF and IPF with severe PH. JAK2-mediated pulmonary artery remodelling in IPF, almost in part, by cell transformations such as HPAEC to mesenchymal transition, and HPASMC to myofibroblast transition and proliferation. JAK2 contributed to 5-HT-induced contraction in small human pulmonary arteries of patients with IPF through the inactivation of $\mathrm{BK}_{\mathrm{ca}}$ channels, the increase of cytoplasmic $\mathrm{Ca}^{2+}$ and the phosphorylation of MLCK in HPASMCs. The animal in vivo model of bleomycin-induced lung fibrosis and $\mathrm{PH}$ demonstrated that JAK2 pharmacological inhibition improves lung tissue fibrosis, right ventricular hypertrophy, pulmonary vascular remodelling and hypertension, improving pulmonary perfusion and $V / Q$ mismatching. Our findings may add scientific value to support treatment of IPF and the associated PH using JAK2 inhibitors.

Previous reports have demonstrated the overexpression and activation of STAT3 in lungs from patients with $\operatorname{IPF}^{15}{ }^{16}$ and 

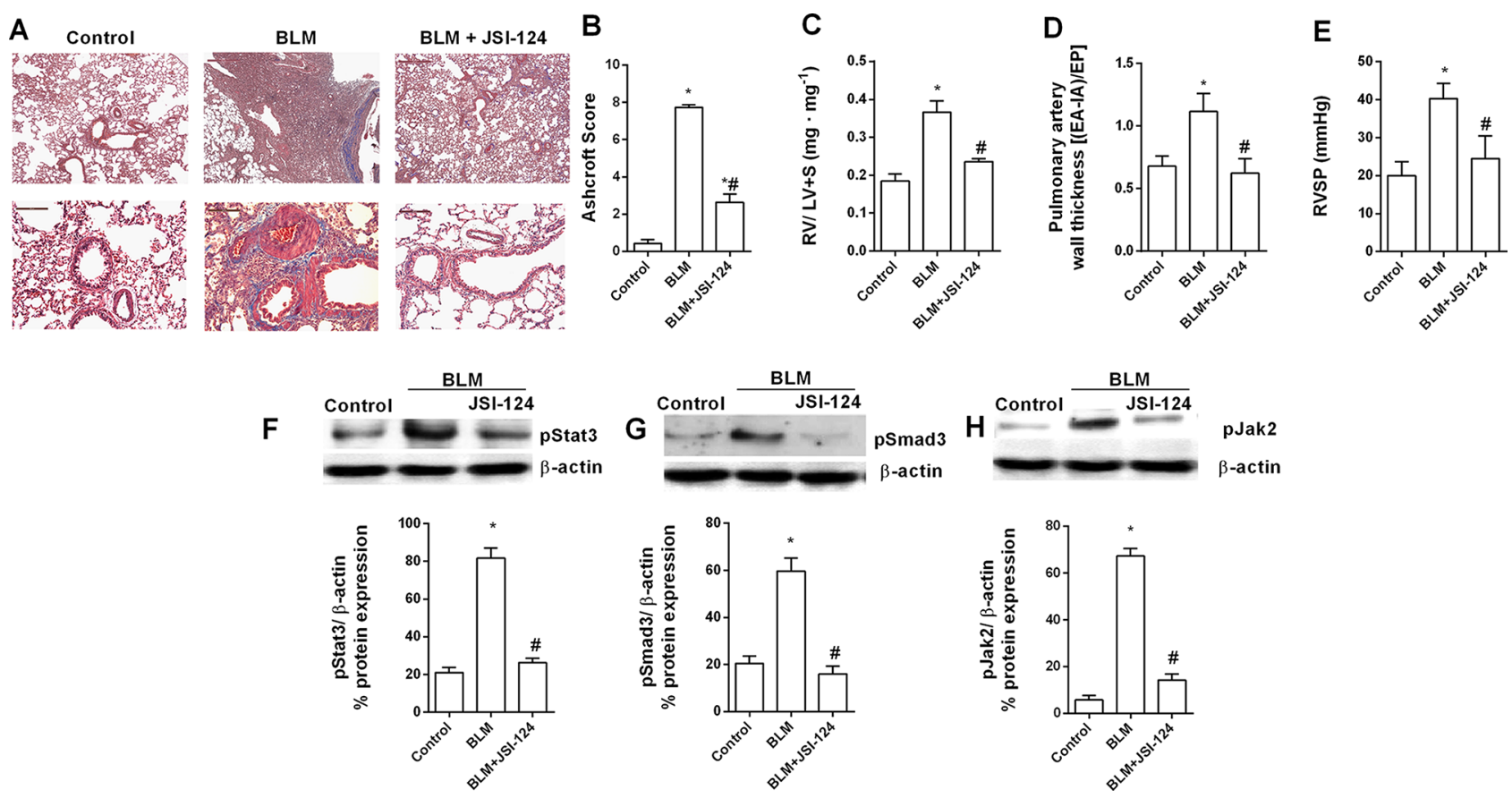

Figure 6 Bleomycin-induced lung fibrosis and pulmonary artery remodelling and hypertension is attenuated by JAK2 inhibition. Wistar rats received a single intratracheal dose of bleomycin (BLM; $3.75 \mathrm{U} / \mathrm{kg}$ ) on day 1 . JSI-124 (1 mg/kg/day i.p.) or vehicle was administered from day 7 until analysis at day 28 ( $n=10$ per group). (A) Masson's trichrome (scale bar: $100 \mu \mathrm{m}$ ) of controls, BLM and BLM+JSI-124. (B) Fibrosis Ashcroft scores were assessed as described in the Methods. (C) Ventricular right hypertrophy, (D) pulmonary artery remodelling and (E) pulmonary artery pressure were measured in different groups at the end of the experimental procedure. $(\mathrm{F}-\mathrm{H}) \mathrm{p}$-Smad, $\mathrm{p}$-Stat and p-Jak2 western blots of lung tissue from control vehicle, BLM and $\mathrm{BLM}+\mathrm{JSI}-124$ groups. Data are expressed as the ratio to $\beta$-actin for \%protein levels. Results are expressed as means $\pm \mathrm{SE}, \mathrm{n}=10$. One-way analysis of variance followed by post hoc Bonferroni tests. ${ }^{*} \mathrm{P}<0.05$ related to controls; $\# \mathrm{P}<0.05$ related to BLM. i.p., intraperitoneal; JAK2, Janus kinase type 2; RVSP, right ventricular systolic pressure.

patients with PH. ${ }^{27}$ STAT3 is a cytoplasmic latent transcription factor that is activated by phosphorylation in response to cytokines such as IL-6, growth factors such as PDGF and agonists such as ET-1 and AT2. Src and JAKs are among the proteins the are most frequently involved in the transduction of the signal between the fixation of the agonist on the receptor and the phosphorylation of STAT3, although many others can activate STAT3 such as G-protein coupled receptors agonists. ${ }^{27}$ Interestingly, p-JAK2 can activate STAT3 and it can activate different intracellular receptors and form multiprotein complexes. ${ }^{28}$ However, the exact role of p-JAK2 in IPF remains to be dissected. In this work, we observed an increased expression of STAT3, JAK2 and its phosphorylated forms in lung tissue and pulmonary arteries from IPF and IPF + PH patients. While the expression of STAT3 was similar in IPF and IPF $+\mathrm{PH}$ groups, the expression of JAK2/ p-JAK2 was significantly overexpressed in IPF $+\mathrm{PH}$ pulmonary arteries suggesting a dominant role on pulmonary artery remodelling. The p-JAK2 nuclear localisation in pulmonary arteries and fibrotic areas suggest a role as non-canonical transcription factor independent of canonical STAT3 pathway. Previous reports have identified nuclear localisation of p-JAK2 supporting our findings. ${ }^{28} 29$ Emerging evidence indicates that the nuclear role of p-JAK2 may be of particular significance under physiological and pathological conditions of heightened cellular growth independently of STAT3 activation. ${ }^{28}$

Some studies have indicated the implication of JAKs proteins in PH, analysing the increase of JAKs mRNA levels in rats with $\mathrm{PH}$ induced by hypoxia ${ }^{30}$ or through the beneficial effect of the JAK2 inhibitor AG490 in reversing PAECs proliferation. ${ }^{31}$ However, other studies failed to determine JAK2 upregulation/activation in HPASMC of patients with pulmonary artery hypertension (PAH), compared with healthy HPASMCs. ${ }^{32}$ Overexpression of p-JAK2 has been observed in cytoplasm of skin fibroblasts from patients with systemic sclerosis $(\mathrm{SSc})^{12}$ and increased especially when associated with PAH, compared with controls and idiopathic PAH where JAK2 levels were not affected. ${ }^{33}$ However, the state of phosphorylation of JAK2 has not been measured in these studies, poorly allowing any conclusion on whether JAK2 is activated.

However, the increase of JAK2 expression and activation in IPF and to a greater extent in IPF + PH could have different meanings. In this respect, pharmacological inhibition of JAK2 and gene silencing of JAK2 inhibited EnMT and HPASMC to myofibroblast transition and proliferation. EnMT has been proposed as cellular mechanism to increase the number of lung myofibroblasts from endothelial cells to increase lung fibrosis in animal and human studies. ${ }^{419}$ Recent studies indicate that EnMT can be mediated through the activation of JAK/STAT3 pathway in endothelial cells from different types of cancer. ${ }^{34}$ Moreover, TGF $\beta 1$ activates JAK2 and STAT3 in SSc, and pharmacological or genetic inactivation of JAK2 reduces the skin profibrotic effects of TGF $\beta 1 .^{12}$ In the present work, we showed first evidence of the phosphorylation of JAK2 after TGFß1 stimulation in both HPAEC and HPASMC of patients with IPF. Furthermore, pharmacological inhibition of JAK2 or gene silencing of JAK2 reduced the TGF 31 -induced SMAD3 phosphorylation that connect TGF $\beta 1$ with JAK2 pathway as previously outlined. ${ }^{35}$ Supporting these results, recent evidence indicates that TGF $\beta 1$ can activate STAT3 via SMAD2/3-dependent mechanism in fibroblasts from patients with IPF. ${ }^{16}$

$\mathrm{PA}$ remodelling in $\mathrm{PH}$ associated to hypoxaemic lung diseases such as chronic obstructive pulmonary disease or IPF 
A

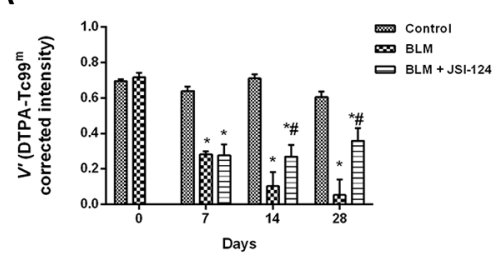

B

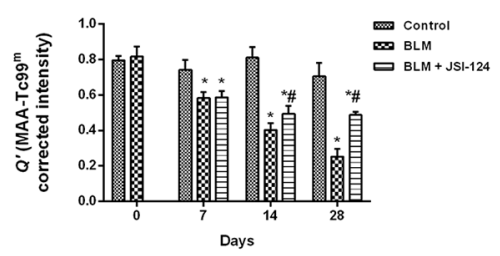

C

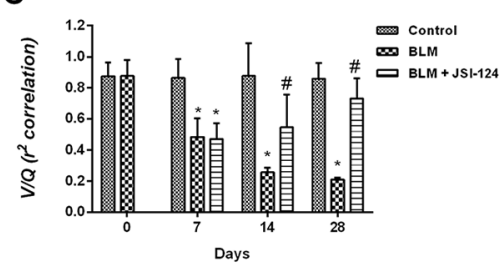

D
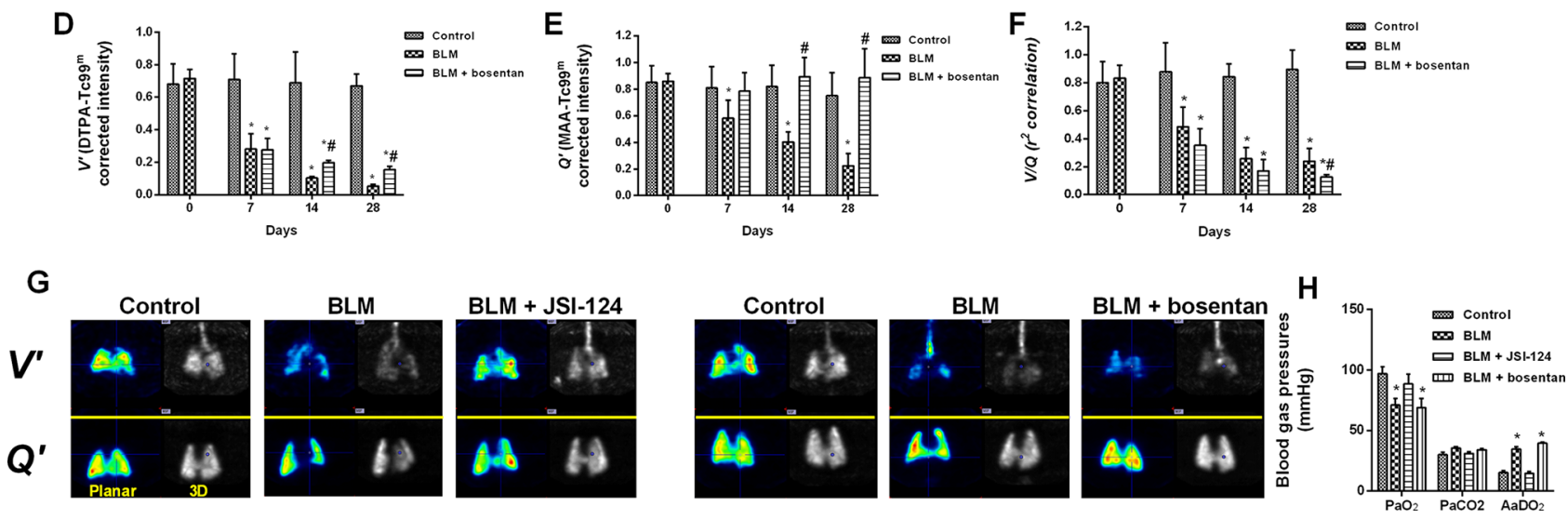

Figure 7 JAK2 inhibition improves pulmonary ventilation, perfusion and ventilation/perfusion (VIQ) mismatch in a rat model of pulmonary fibrosis and pulmonary hypertension induced by bleomycin. A single $3.75 \mathrm{U} / \mathrm{kg}$ dose of BLM or vehicle was administered intratracheally on day 0 . (A-C) JSI-124 (1 mg/kg/day i.p.) or (D-F) bosentan (100 mg/kg/day oral) were administered from day 7 to day 28 . Lung ventilation was measured by DTPA$\mathrm{Tc}^{\mathrm{m}}$ inhalation, and perfusion was measured by injection of MAA-Tc99 ${ }^{\mathrm{m}}$ via the tail vein at days 7, 14 and 28 of the experimental procedure. Lung signal was measured using micro-CT-coupled to single-photon emission CT. (C andF) The relationship between the ventilation (V) and perfusion (Q) data was determined using PMOD software to analyse the intensity of radiation (arbitrary units) of each volume of interest. (A-F) The figures show the mean $\pm \mathrm{SE}$ of the corrected radiation intensity of the radiation signal of each pixel of the 250 images of $V$ and $Q$. (G) Representative $V$ and $Q$ images. (H) Arterial blood gas pressures measured at day 28 of the experimental procedure. Results were analysed in 10 animals/ experimental condition. One-way analysis of variance followed by Bonferroni post hoc tests. ${ }^{*} \mathrm{P}<0.05$ compared with control; $\# \mathrm{P}<0.05$ compared with BLM. $\mathrm{AaDO}_{2}$ alveolar- arterial $\mathrm{O}_{2}$ pressure difference; $\mathrm{BLM}$, bleomycin; i.p., intraperitoneal; JAK2, Janus kinase type 2; $\mathrm{PaCO}_{2}$, arterial blood $\mathrm{CO}_{2}$ pressures; $\mathrm{PaO}_{2}$ arterial blood $\mathrm{O}_{2}$ pressure.

is characterised by remodelling of the intimal and, in a lesser extent, medial layer of muscular arteries but not in adventitia. ${ }^{36}$ The high expression of JAK2/STAT3 in the intimal layer and media may reflect the active, proliferative and migratory phenotype of intimal resident cells that are mainly myofibroblasts. ${ }^{37}$ Therefore, the implication of JAK2 in EnMT and smooth muscle cell to myofibroblast transition could link the intimal and media remodelling and the high amount of myofibroblasts in these artery layers.

In addition to TGF $\beta 1$, other profibrotic factors such as PDGF, VEGF, IL-6, IL-13, AT2, 5-HT and ET-1 can phosphorylate JAK2 $2^{13} 14$ and are elevated in pulmonary arteries from IPF and IPF $+\mathrm{PH}$ patients as we showed in this work and previously reported. ${ }^{18}$ In addition to pulmonary fibrosis, 5-HT, ET-1 and AT2 promotes pulmonary artery vasoconstriction, pulmonary remodelling and $\mathrm{PH}$ in addition to lung fibrosis. ${ }^{38} 39$ Previous reports have shown that JAK2 inhibition can reduce intracellular $\mathrm{Ca}^{2+}$ and rat aortic rings contraction induced by 5 -HT, ET-1 and AT2. ${ }^{38}{ }^{39}$ In this work, we showed first evidence on the role of JAK2 in pulmonary vasoconstriction of small pulmonary arteries from control subjects, IPF and $\mathrm{IPF}+\mathrm{PH}$ patients. It is known that human pulmonary artery vascular remodelling occurs on small resistant-type intrapulmonary vessels that form part of the pulmonary vascular bed responsible for the pressure elevation observed in $\mathrm{PH}^{40}$ In this work, the inhibition of JAK2 using JSI-124 as pharmacological approach relaxed 5-HT precontracted small pulmonary arteries of patients with IPF. Furthermore, JSI-124 had direct relaxing effects on untreated basal pulmonary arteries, which suggest a role of JAK2 maintaining basal tone of IPF pulmonary arteries. Interestingly, vascular relaxing effects of JSI-124 were more potent in small pulmonary arteries from control patients than in IPF and IPF $+\mathrm{PH}$, respectively, suggesting a preference of relaxation depending on the nature/remodelling status of pulmonary arteries. Pulmonary artery relaxation induced by JSI-124 was independent of the pulmonary endothelium but dependent of potassium channels. In fact, IBTX, an inhibitor of large conductance calcium-activated potassium channel $\mathrm{BK}_{\mathrm{Ca}}$, reduced the relaxing effects of JSI-124. Electrophysiological experiments using patch clamp technique showed that JAK2 inhibition increased $\mathrm{BK}_{\mathrm{Ca}}$ currents and that JAK2 inhibition or gene silencing reduced the increase of intracellular $\mathrm{Ca}^{2+}$ induced by $\mathrm{BK}_{\mathrm{Ca}}$ blockage.

A feature of all contractile HPASMCs is the abundant expression of $\mathrm{BK}_{\mathrm{Ca}}$ channels that are voltage dependent, increasing in activity in response to membrane depolarisation. ${ }^{41} \mathrm{~A}$ function of the $\mathrm{BK}_{\mathrm{Ca}}$ channels is to provide negative feedback against depolarisation, limiting $\mathrm{Ca}^{2+}$ influx through $\mathrm{Ca}_{\mathrm{v}} 1.2$ (L-type voltage-gated $\mathrm{Ca} 2+$ ) channels. Therefore, the dominant channels in regulation of vascular tone are $\mathrm{BK}_{\mathrm{Ca}}$ channels of the HPASMCs.

In addition, and of direct relevance to microvascular smooth muscle, $\mathrm{BK}_{\mathrm{Ca}}$ is activated by both $\mathrm{Ca}^{2+}$ and voltage to act as a negative feedback control mechanism for contractile stimuli while being sensitive to a number of metabolic stimuli such 
as partial pressure of oxygen, reactive oxygen species, phosphorylation by protein kinases, steroid hormones and fatty acids and their metabolites. Importantly, a number of vasodilator and vasoconstrictor stimuli use phosphorylation-mediated mechanisms to regulate ion channel activities. In general, PASMC $\mathrm{BK}_{\mathrm{C}}$ is activated by cAMP/PKA ${ }^{42}$ and $\mathrm{cGMP} / \mathrm{PKG}^{42}$ while being inhibited by $\mathrm{PKC}^{43}$ and the tyrosine kinase $\mathrm{c}-\mathrm{Src}^{44}{ }^{4} \mathrm{Also}$, hypoxic conditions downregulate the expression and activity of $\mathrm{BK}_{\mathrm{C}_{2}}$ channels that contribute to the elevated pulmonary vascular tone found in PAH. ${ }^{45}$ In fact, genetic deletion of the $\beta 1$ subunit of $\mathrm{BK}_{\mathrm{C}}$ in mice leads to hypertension and increased contractility of vascular smooth muscle cells. ${ }^{46}{ }^{47}$ Furthermore, transformed and dedifferentiated smooth muscle cells into proliferative remodelling phenotype are accompanied by the loss of $\mathrm{BK}_{\mathrm{C}_{2}}$ channel expression, thus increasing pulmonary wall remodelling. ${ }^{48}$

In this regard, results obtained in this study showed a decreased expression of $\mathrm{BK}_{\mathrm{C}_{2}} \alpha 1$ and $\mathrm{BK}_{\mathrm{C}} \beta 1$ in pulmonary arteries from $\mathrm{IPF}$, and in a greater extent in IPF $+\mathrm{PH}$ pulmonary arteries, which may explain, almost in part, the lowest relaxing effects of JSI-124 in pulmonary arteries from IPF and IPF + PH patients compared with control subjects and also the lowest effect of JASI-124 inhibiting hypoxic pulmonary vasconstriction in IPF pulmonary arteries.

These results are of potential value, since pulmonary vasodilation in poorly ventilated areas, as occurs in IPF, increase $V / Q$ mismatch and oxygen desaturation. This is the case of vasodilators approved in PAH and used to treat PH in IPF. In this work, we observed an overexpression and activation of JAK2 in pulmonary arteries from IPF and IPF $+\mathrm{PH}$ patients, contributing to pulmonary artery remodelling. Low expression of $\mathrm{BK}_{\mathrm{C}}$ in pulmonary arteries from $\mathrm{IPF}+\mathrm{PH}$ indicated a preferental relaxation in well-ventilated alveolar units. To directly analyse the role of the JAK2 inhibitor JSI-124 on the V/Q matching, we used $V / Q$ micro-CT-SPECT imaging, a well-established nuclear medicine technique that provides spatial information of respiratory gas exchange, ventilation of alveolar units and perfusion of the pulmonary capillary beds. ${ }^{18}$ Therapeutic administration of JSI-124 from day 7 to day 28 of the experimental procedure improved rat pulmonary artery remodelling, right ventricle hypertrophy, $\mathrm{PH}$, ventilation, lung blood perfusion and $V / Q$ mismatching induced by bleomycin. In contrast, bosentan predominantly increased perfusion and in a lesser extent ventilation, showing a mild impairment of $V / Q$ as previously outlined. ${ }^{49}$ Although results provided in this work relates JAK2 with IPF and $\mathrm{PH}$, it should be noted that human samples used are from no more than 10 patients, a small sample that can limit the interpretation of this work.

To our knowledge, this is the first report that provides evidence on the JAK2 participation in lung fibrosis and pulmonary remodelling and vasoconstriction of IPF and IPF $+\mathrm{PH}$ patients that may be of potential value since JAK2 inhibitors are already in clinical use for other indications.

\footnotetext{
Author affiliations

${ }^{1}$ Department of Pharmacology, Faculty of Medicine, Jaume I University, Castellón de la Plana, Spain

${ }^{2}$ Pharmacy Unit, University General Hospital Consortium, Valencia, Spain

${ }^{3}$ CIBERES, Health Institute Carlos III, Valencia, Spain

${ }^{4}$ Department of Pharmacology, Faculty of Medicine, University of Valencia, Valencia, Spain

${ }^{5}$ Thoracic Surgery Unit, University and Polytechnic Hospital La Fe, Valencia, Spain

${ }^{6}$ Respiratory Unit, University General Hospital Consortium, Valencia, Spain

${ }^{7}$ Department of Pharmacology, School of Medicine, Universidad Complutense de Madrid, Madrid, Spain

${ }^{8}$ Department of Thoracic Surgery, University General Hospital Consortium, Valencia, Spain
}

${ }^{9}$ Surgery Unit, University General Hospital Consortium, Valencia, Spain

${ }^{10}$ Health Research Institute INCLIVA, Valencia, Spain

${ }^{11}$ Research and teaching Unit, University General Hospital Consortium, Valencia, Spain

Acknowledgements We would like to thank the personnel of the Department of Pathology at the General University Hospital of Valencia and the animal housing facilities of the University of Valencia, Spain.

Contributors Conception and design: JM, BB, AM, JLO, FP-V, AC and JC. Data acquisition: JM, JE, EP, EA, EF, AC, EM and JC. Analysis and interpretation: all authors.

Funding This work was supported by the grants SAF2014-55322-P (JC), SAF2011-28150 (FPV) and SAF2014-55399-R, FIS PI14/01733 (JM), FIS PI17/02158 (JM), SAF2015-65368-R (EM), CIBERES (CB06/06/0027), TRACE (TRA2009-0311; Spanish Government) and by research grants from the Regional Government Prometeo II/2013/014 (JC, EM and JM) and ACIF/2016/341 (BB) from 'Generalitat Valenciana'.

Disclaimer Funding entities did not contribute to the study design or data collection, analysis and interpretation nor to the writing of the manuscript.

Competing interests None declared.

Patient consent Obtained.

Ethics approval This study has been approved by the ethics committee of the University General Hospital of Valencia, Spain (CEIC22/2013)

Provenance and peer review Not commissioned; externally peer reviewed.

(c) Article author(s) (or their employer(s) unless otherwise stated in the text of the article) 2018. All rights reserved. No commercial use is permitted unless otherwise expressly granted.

\section{REFERENCES}

1 Lettieri CJ, Nathan SD, Barnett SD, et al. Prevalence and outcomes of pulmonary arterial hypertension in advanced idiopathic pulmonary fibrosis. Chest 2006:129:746-52.

2 Heath D, Gillund TD, Kay JM, et al. Pulmonary vascular disease in honeycomb lung. J Pathol Bacteriol 1968;95:423-30.

3 Blanco I, Ribas J, Xaubet A, et al. Effects of inhaled nitric oxide at rest and during exercise in idiopathic pulmonary fibrosis. J App/ Physiol 2011;110:638-45.

4 Hashimoto N, Phan SH, Imaizumi K, et al. Endothelial-mesenchymal transition in bleomycin-induced pulmonary fibrosis. Am J Respir Cell Mol Biol 2010;43:161-72.

5 Yeager ME, Frid MG, Stenmark KR. Progenitor cells in pulmonary vascular remodeling. Pulm Circ 2011;1:3-16.

6 Caminati A, Cassandro R, Harari S. Pulmonary hypertension in chronic interstitial lung diseases. Eur Respir Rev 2013;22:292-301.

7 Smith JS, Gorbett D, Mueller J, et al. Pulmonary hypertension and idiopathic pulmonary fibrosis: a dastardly duo. Am J Med Sci 2013;346:221-5.

8 Granzow M, Schierwagen R, Klein S, et al. Angiotensin-Il type 1 receptor-mediated Janus kinase 2 activation induces liver fibrosis. Hepatology 2014;60:334-48.

9 Tang J, Liu CY, Lu MM, et al. Fluorofenidone protects against renal fibrosis by inhibiting STAT3 tyrosine phosphorylation. Mol Cell Biochem 2015;407:77-87.

10 Wang L, Li J, Li D. Losartan reduces myocardial interstitial fibrosis in diabetic cardiomyopathy rats by inhibiting JAK/STAT signaling pathway. Int I Clin Exp Pathol 2015;8:466-73.

11 Zahr AA, Salama ME, Carreau N, et al. Bone marrow fibrosis in myelofibrosis: pathogenesis, prognosis and targeted strategies. Haematologica 2016;101:660-71.

12 Zhang Y, Dees C, Beyer C, et al. Inhibition of casein kinase II reduces TGF $\beta$ induced fibroblast activation and ameliorates experimental fibrosis. Ann Rheum Dis 2015; 74:936-43

13 Rane SG, Reddy EP. Janus kinases: components of multiple signaling pathways. Oncogene 2000;19:5662-79.

14 Roskoski R. Janus kinase (JAK) inhibitors in the treatment of inflammatory and neoplastic diseases. Pharmacol Res 2016;111:784-803.

15 Pechkovsky DV, Prêle CM, Wong J, et al. STAT3-mediated signaling dysregulates lung fibroblast-myofibroblast activation and differentiation in UIP/IPF. Am J Pathol 2012;180:1398-412.

16 Pedroza M, Le TT, Lewis K, et al. STAT-3 contributes to pulmonary fibrosis through epithelial injury and fibroblast-myofibroblast differentiation. Faseb J 2016;30:129-40.

17 Prêle CM, Yao E, O'Donoghue RJ, et al. STAT3: a central mediator of pulmonary fibrosis? Proc Am Thorac Soc 2012;9:177-82.

18 Milara J, Escrivá J, Ortiz JL, et al. Vascular effects of sildenafil in patients with pulmonary fibrosis and pulmonary hypertension: an ex vivo/in vitro study. Eur Respir J 2016:47:1737-49.

19 Almudéver P, Milara J, De Diego A, et al. Role of tetrahydrobiopterin in pulmonary vascular remodelling associated with pulmonary fibrosis. Thorax 2013;68:938-48.

20 Ashcroft T, Simpson JM, Timbrell V. Simple method of estimating severity of pulmonary fibrosis on a numerical scale. J Clin Pathol 1988:41:467-70. 
21 Milara J, Mata M, Mauricio MD, et al. Sphingosine-1-phosphate increases human alveolar epithelial IL-8 secretion, proliferation and neutrophil chemotaxis. Eur J Pharmacol 2009;609:132-9.

22 Milara J, Gabarda E, Juan G, et al. Bosentan inhibits cigarette smoke-induced endothelin receptor expression in pulmonary arteries. Eur Respir J 2012;39:927-38.

23 Cortijo J, Milara J, Mata M, et al. Nickel induces intracellular calcium mobilization and pathophysiological responses in human cultured airway epithelial cells. Chem Biol Interact 2010;183:25-33.

24 Cogolludo A, Moreno L, Lodi F, et al. Postnatal maturational shift from PKCzeta and voltage-gated $\mathrm{K}+$ channels to RhoA/Rho kinase in pulmonary vasoconstriction. Cardiovasc Res 2005:66:84-93.

25 Kilkenny C, Browne WJ, Cuthill IC, et al. Improving bioscience research reporting: the ARRIVE guidelines for reporting animal research. PLoS Biol 2010;8:e1000412.

26 Nefedova Y, Nagaraj S, Rosenbauer A, et al. Regulation of dendritic cell differentiation and antitumor immune response in cancer by pharmacologic-selective inhibition of the janus-activated kinase 2/signal transducers and activators of transcription 3 pathway. Cancer Res 2005:65:9525-35.

27 Paulin R, Meloche J, Bonnet S. STAT3 signaling in pulmonary arterial hypertension. JAKSTAT 2012;1:223-33.

28 Zouein FA, Duhé RJ, Booz GW. JAKs go nuclear: emerging role of nuclear JAK1 and JAK2 in gene expression and cell growth. Growth Factors 2011;29:245-52.

29 Qian C-J, Yao J, Si J-M. Nuclear JAK2: form and function in cancer. Anat Rec 2011;294:1446-59.

30 Wang GS, Qian GS, Mao BL, et al. [Changes of interleukin- 6 and Janus kinases in rats with hypoxic pulmonary hypertension]. Zhonghua Jie He He Hu Xi Za Zhi 2003:26:664-7.

31 Masri FA, Xu W, Comhair SA, et al. Hyperproliferative apoptosis-resistant endothelial cells in idiopathic pulmonary arterial hypertension. Am J Physiol Lung Cell Mol Physio 2007;293:L548-54.

32 Courboulin A, Paulin R, Giguère NJ, et al. Role for miR-204 in human pulmonary arterial hypertension. J Exp Med 2011;208:535-48.

33 Christmann RB, Hayes E, Pendergrass S, et al. Interferon and alternative activation of monocyte/macrophages in systemic sclerosis-associated pulmonary arterial hypertension. Arthritis Rheum 2011;63:1718-28.

34 Magrini E, Villa A, Angiolini F, et al. Endothelial deficiency of L1 reduces tumor angiogenesis and promotes vessel normalization. J Clin Invest 2014;124:4335-50.

35 Liu RY, Zeng Y, Lei Z, et al. JAK/STAT3 signaling is required for TGF- $\beta$-induced epithelial-mesenchymal transition in lung cancer cells. Int J Oncol 2014;44:1643-51.
36 Hoffmann J, Wilhelm J, Marsh LM, et al. Distinct differences in gene expression patterns in pulmonary arteries of patients with chronic obstructive pulmonary disease and idiopathic pulmonary fibrosis with pulmonary hypertension. Am J Respir Crit Care Med 2014;190:98-111.

37 Stacher E, Graham BB, Hunt JM, et al. Modern age pathology of pulmonary arterial hypertension. Am J Respir Crit Care Med 2012;186:261-72.

38 Bhaskaran S, Zaluski J, Banes-Berceli A. Molecular interactions of serotonin (5-HT) and endothelin-1 in vascular smooth muscle cells: in vitro and ex vivo analyses. Am J Physiol Cell Physiol 2014;306:C143-51.

39 Wallace TA, Xia SL, Sayeski PP. Jak2 tyrosine kinase prevents angiotensin IImediated inositol 1,4,5 trisphosphate receptor degradation. Vascul Pharmacol 2005;43:336-45

40 Rabinovitch M, Gamble W, Nadas AS, et al. Rat pulmonary circulation after chronic hypoxia: hemodynamic and structural features. Am J Physiol 1979:236:H818-27.

41 Wei AD, Gutman GA, Aldrich R, et al. International Union of Pharmacology. LII. Nomenclature and molecular relationships of calcium-activated potassium channels. Pharmacol Rev 2005;57:463-72.

42 Schubert R, Nelson MT. Protein kinases: tuners of the BKCa channel in smooth muscle. Trends Pharmacol Sci 2001;22:505-12.

43 Schubert R, Noack T, Serebryakov VN. Protein kinase $C$ reduces the KCa current of rat tail artery smooth muscle cells. Am J Physiol 1999;276:C648-58.

44 Alioua A, Mahajan A, Nishimaru K, et al. Coupling of c-Src to large conductance voltage- and $\mathrm{Ca} 2+$-activated $\mathrm{K}+$ channels as a new mechanism of agonist-induced vasoconstriction. Proc Natl Acad Sci U S A 2002;99:14560-5

45 Peng W, Hoidal JR, Karwande SV, et al. Effect of chronic hypoxia on K+ channels: regulation in human pulmonary vascular smooth muscle cells. Am J Physiol 1997:272:C1271-8.

46 Brenner R, Peréz GJ, Bonev AD, et al. Vasoregulation by the beta1 subunit of the calcium-activated potassium channel. Nature 2000;407:870-6.

47 Plüger S, Faulhaber J, Fürstenau M, et al. Mice with disrupted BK channel beta1 subunit gene feature abnormal $\mathrm{Ca}(2+)$ spark/STOC coupling and elevated blood pressure. Circ Res 2000:87:E53-60.

48 Beech DJ. Ion channel switching and activation in smooth-muscle cells of occlusive vascular diseases. Biochem Soc Trans 2007:35:890-4.

49 Becker EM, Stasch JP, Bechem M, et al. Effects of different pulmonary vasodilators on arterial saturation in a model of pulmonary hypertension. PLoS One 2013;8:e73502. 